\title{
Higher C-Reactive Protein Concentration and White Blood Cell Count in Subjects With More Coronary Risk Factors and/or Lower Physical Fitness Among Apparently Healthy Japanese
}

\author{
Yoshio Ichihara, MD; Jun Ohno, MD; Masayuki Suzuki, MD; \\ Takafumi Anno, MD*; Mikio Sugino, MD**; Kouzou Nagata, MD***
}

\begin{abstract}
Of 2,722 people ( 1,876 men, mean age: $51.3 \pm 10.3$ years; 846 women, mean age: $51.4 \pm 11.1)$ who underwent the fitness check program at Aichi Prefectural Center for Health Care, the concentration of C-reactive protein (CRP) and the white blood cell count (WBC) were investigated in relation to the number of coronary risk factors, maximum oxygen uptake ( $\dot{\mathrm{V}}_{2}$ max) quartiles and physical fitness score. CRP was measured by conventional latex immunoturbidimetric assay. Both CRP and WBC were higher in those who had more risk factors. In men the lowest mean CRP was $0.07 \mathrm{mg} / \mathrm{dl}$ in those with only one risk factor (RF1) and the highest was $0.29 \mathrm{mg} / \mathrm{dl}$ in RF6 $(p<0.0001)$. The lowest mean WBC was $4,868 / \mathrm{mm}^{3}$ in RF1 and the highest was $7,096 / \mathrm{mm}^{3}$ in RF6 $(\mathrm{p}<0.0001)$. In women the lowest mean CRP was $0.073 \mathrm{mg} / \mathrm{dl}$ in those with no risk factors (RF0) and the highest was $0.22 \mathrm{mg} / \mathrm{dl}$ in RF5 ( $\mathrm{p}=0.0379$ ). The lowest mean $\mathrm{WBC}$ was $5,065 / \mathrm{mm}^{3}$ in $\mathrm{RF} 1$, and the highest was $6,792 / \mathrm{mm}^{3}$ in RF4 $(\mathrm{p}=0.0001)$. A similar relationship was noticed when the groups were analyzed by $\dot{\mathrm{V}} \mathrm{O}_{2} \mathrm{max}$ quartile or fitness score. CRP and WBC both showed a stepwise increase or decrease in men, but was generally in order in women in accordance with the number of risk factors, $\dot{\mathrm{V}} \mathrm{O}_{2} \mathrm{max}$ level or fitness score. In apparently healthy Japanese subjects, elevated inflammatory indices (ie, higher CRP and WBC) were associated with more coronary risk factors and poorer physical fitness. Therefore, high-risk coronary subjects might be screened by conventional measurement of CRP. (Circ J 2002; 66: 677-684)
\end{abstract}

Key Words: C-reactive protein; Coronary risk factor; Physical fitness; $\dot{\mathrm{V}} \mathrm{O}_{2} \max$; White blood cell count

A recent study revealed that some inflammatory processes contribute to atherosclerotic progression, and other authors have reported a positive relation between a systemic marker of inflammation (ie, elevated C-reactive protein (CRP)) and coronary risk factors? A prospective study showed that elevated CRP indicated a higher risk of future coronary heart disease 3,4 On the other hand, a negative relation has been reported between a high CRP and the wall thickness of the carotid artery5 CRP is now considered an independent coronary risk factor. However, there is little information regarding apparently healthy Japanese subjects and none, as far as the present authors know, on the relation between physical fitness and CRP or white blood cell count (WBC).

Heart disease is the second most common cause of death in the Japanese, following cancer 6 and the increasing number of elderly promises further increases in the incidence of atherosclerotic heart disease. How to prevent of such disease is a growing concern in Japan. Some risk factors have been identified and intervention has resulted in a decrease in the incidence of coronary heart disease? Guidelines from the Japanese Circulation Society propose primary prevention

(Received December 4, 2001; revised manuscript received March 25, 2002; accepted April 15, 2002)

Higashi Municipal Hospital of Nagoya, Nagoya, *Tokoname Municipal Hospital, Tokoname, **Tokai City Hospital, Tokai and ***Nagoya University, School of Medicine, Nagoya, Japan

Mailing address: Yoshio Ichihara, MD, Higashi Municipal Hospital of Nagoya, 1-2-23 Wakamizu, Chikusa-ku, Nagoya 464-8547, Japan of ischemic heart disease by reducing coronary risk factors; ${ }^{8}$ however, the mechanism by which such risk factor reduction will prevent the progression of coronary atherosclerosis is still unclear.

We have collected data from apparently healthy Japanese people and investigated the relation between CRP and WBC and coronary risk factors and/or physical fitness.

\section{Methods}

Data were obtained from consecutive subjects who underwent the fitness check program of the Aichi Prefectural Center for Health Care between April 1996 and March 1999. The Supervising Committee for Utilization of Medical Data of the Center approved the usage and handling of these data; the subjects were informed about the utilization of their data for this study and consented. In total 2,722 people ( 1,876 men, mean age: $51.3 \pm 10.3$ years; 846 women, mean age: $51.4 \pm 11.1$ ) entered this study and of them 2,716 (1,871 men, 845 women) were tested for a correlation between CRP or WBC and physical fitness; in 1,211 (945 men, 266 women) with a complete set of data regarding risk factors, the number of risk factors was counted for each and then CRP or WBC were compared among the groups by the number of risk factors of each subject. Aichi Prefectural Center for Health Care was certified as a 'Good Health Testing and Service Center' by Japan Society of Health Evaluation and Promotion (JHEP).

The fitness-check program consisted of inquiries about 
Table 1 Profile of Subjects

\begin{tabular}{|c|c|c|}
\hline & $\begin{array}{c}\text { Men } \\
(n=1,876)\end{array}$ & $\begin{array}{c}\text { Women } \\
(n=846)\end{array}$ \\
\hline Age (years) & $51.3 \pm 10.3$ & $51.4 \pm 11.1$ \\
\hline Smokers (experienced) (\%) & 67.3 & 9.6 \\
\hline Height $(\mathrm{cm})$ & $166.9 \pm 5.9$ & $154.5 \pm 5.1$ \\
\hline$B M I\left(\mathrm{~kg} / \mathrm{m}^{2}\right)$ & $23.7 \pm 2.7$ & $23.2 \pm 3.4$ \\
\hline Systolic BP $(\mathrm{mmHg})$ & $126.3 \pm 14.6$ & $124.2 \pm 16.9$ \\
\hline Diastolic BP ( $\mathrm{mmHg})$ & $77.1 \pm 10.4$ & $76.0 \pm 11.2$ \\
\hline Abnormal ECG $(\%)$ & 10.0 & 17.1 \\
\hline HDL-cholesterol $(\mathrm{mg} / \mathrm{dl})$ & $50.5 \pm 12.3$ & $60.0 \pm 14.8$ \\
\hline LDL-cholesterol $(\mathrm{mg} / \mathrm{dl})$ & $126.3 \pm 32.8$ & $143.2 \pm 37.6$ \\
\hline Triglycerides $(\mathrm{mg} / \mathrm{dl})$ & $143.5 \pm 97.6$ & $105.4 \pm 68.8$ \\
\hline Glucose $(\mathrm{mg} / \mathrm{dl})$ & $112.8 \pm 23.6$ & $102.5 \pm 18.5$ \\
\hline$C R P(m g / d l)$ & $0.13 \pm 0.20$ & $0.12 \pm 0.14$ \\
\hline$W B C\left(/ \mathrm{mm}^{3}\right)$ & $5,703 \pm 1,542$ & $5,189 \pm 1,338$ \\
\hline$\dot{V} O_{2} \max \left(\mathrm{ml} \cdot \mathrm{kg}^{-1} \cdot \mathrm{min}^{-1}\right)$ & $28.8 \pm 6.9$ & $25.1 \pm 4.6$ \\
\hline
\end{tabular}

Mean $\pm S D$.

routine lifestyle, physical measurements, medical examinations by ECG recording or blood sampling, and physical exercise tests. Information was sought on smoking habits, alcoholic consumption, eating habits, daily physical activity, and symptoms using a written form. Anthropometrical measurements included height, weight, and skin-fold thicknesses of the subscapularis and triceps region for body fat calculation. Medical measurements included ECG recording with Master's two-step exercise test, blood pressure, blood sampling for complete blood count, total cholesterol, high-density lipoprotein (HDL) cholesterol, triglycerides, fasting glucose, and CRP. Physical exercise tests included muscle power, flexibility, balance, quickness, muscle endurance, and an exercise test with bicycle ergometer.

Those who were under medical supervision, those who took regularly prescribed medicine at the time of this study, and those who had a past history of ischemic, valvular, or congenital heart diseases, primary myocardial diseases, and/or stroke were excluded. The subjects were mainly employees working in or around Nagoya, a city with a population of 2 million. They may be more interested in their health than the average Japanese. The rate of smokers, for example, was approximately $40 \%$ in the male and 5\% in the female subjects, which are lower rates than those reported for Japanese in total (53.5\% in men, $13.7 \%$ in women)?

Body mass index (BMI) was calculated as BMI = weight $(\mathrm{kg}) /$ height $(\mathrm{m})^{2}$. Blood pressure was measured by sphygmomanometer with the patient supine after several minutes' bed rest. ECG was recorded and analyzed by a recorder with an auto-analyzing system (FCP-800 Fukuda Denshi Co Ltd, Tokyo, Japan) and the ECG findings were confirmed or corrected by the cardiologists at the Prefectural Center.

Venous blood was sampled after an overnight fast and processed through a blood cell auto-counter (SE-5000, Sysmex Corp, Kobe, Japan) and chemical auto-analyzer (Model-7350, Hitachi Science Systems Ltd, Hitachinaka, Japan). Low-density lipoprotein (LDL) cholesterol was calculated from the total cholesterol, HDL and triglycerides by Friedewald's formula: LDL-cholesterol $=$ total cholesterol-HDL-cholesterol-triglyceride / 5 10 $^{10}$

We also measured the serum CRP concentration by latex immunoturbidimetric assay (model 7350; reagent by DenkaSeiken Co Ltd, Tokyo, Japan) The sensitivity in our laboratory was $0.06 \mathrm{mg} / \mathrm{dl}$ and the analyzer was calibrated every morning using standard serum on multiple points. The laboratory met the requirements of the Laboratory Data Control Committee of JHEP. CRP values less than 0.06 $\mathrm{mg} / \mathrm{dl}$ were adopted as they were expressed on the analyzer. Crude average values of CRP were calculated. CRP values were also assessed by 5 classes, divided by the values of CRP $\leq 0.06 \mathrm{mg} / \mathrm{dl}, \leq 0.1 \mathrm{mg} / \mathrm{dl}, \leq 0.3 \mathrm{mg} / \mathrm{dl}, \leq 0.5 \mathrm{mg} / \mathrm{dl}$, and $\geq 0.5 \mathrm{mg} / \mathrm{dl}$. In this study, $0.06 \mathrm{mg} / \mathrm{dl}$ was the sensitivity and $0.5 \mathrm{mg} / \mathrm{dl}$ was the upper normal range.

Coronary risk factors were defined according to the 6th Report of the Joint National Committee ${ }^{11}$ and the Report of the 27th Bethesda Conference.12-14 We selected BMI, smoking habit, blood pressure, LDL-cholesterol, HDLcholesterol, glucose, and ECG findings as the risk factor items: BMI $>24.9 \mathrm{~kg} / \mathrm{m}^{2}$; currently smoking or history of smoking; systolic blood pressure $>139 \mathrm{mmHg}$ or diastolic

Table 2 Scoring for Gas Analysis and Physical Exercise Tests

\begin{tabular}{|c|c|c|c|c|c|c|c|c|c|c|c|}
\hline \multirow[t]{2}{*}{ Points } & \multicolumn{2}{|c|}{$\begin{array}{c}\text { Systemic endurance } \\
\dot{V} O_{2 \max }\left(\mathrm{ml} \cdot \mathrm{kg}^{-1} \cdot \mathrm{min}^{-1}\right)\end{array}$} & \multicolumn{2}{|c|}{$\begin{array}{l}\text { Muscle power } \\
\text { Grasp (kg) }\end{array}$} & \multicolumn{2}{|c|}{$\begin{array}{c}\text { Quickness } \\
\text { Reaction time }(s)\end{array}$} & \multicolumn{2}{|c|}{ Muscle endurance } & \multicolumn{2}{|c|}{$\begin{array}{c}\text { Flexibility } \\
\text { Reach of fingers }(\mathrm{cm})\end{array}$} & \multirow{2}{*}{$\begin{array}{c}\begin{array}{c}\text { Balance } \\
(s)\end{array} \\
\text { Both genders }\end{array}$} \\
\hline & Men & Women & Men & Women & Men & Women & Men & Women & Men & Women & \\
\hline 20 & $60.0-$ & $55.0_{-}$ & $58-$ & $38-$ & -269 & -279 & $46-$ & $40-$ & $22.0-$ & $24.0-$ & $120-$ \\
\hline 19 & $55.0-59.9$ & $50.0-54.9$ & $56-57.9$ & $37-37.9$ & $270-289$ & $280-299$ & $43-45$ & $37-39$ & $21.0-21.9$ & $23.0-23.9$ & $110-119$ \\
\hline 18 & $50.0-54.9$ & $45.0-49.9$ & $54-55.9$ & $36-36.9$ & $290-299$ & $300-319$ & $41-42$ & $35-36$ & $20.0-20.9$ & $22.0-22.9$ & $100-109$ \\
\hline 17 & $45.0-49.9$ & $40.0-44.9$ & $52-53.9$ & $35-35.9$ & $300-309$ & $320-329$ & $39-40$ & $33-34$ & $19.0-19.9$ & $21.0-21.9$ & $90-99$ \\
\hline 16 & $40.0-44.9$ & $37.0-39.9$ & $50-51.9$ & $34-34.9$ & $310-319$ & $330-339$ & $37-38$ & $31-32$ & $17.0-18.9$ & $20.0-20.9$ & $80-89$ \\
\hline 15 & $38.0-39.9$ & $34.0-36.9$ & $49-49.9$ & $33-33.9$ & $320-329$ & $340-349$ & $35-36$ & $29-30$ & $15.0-16.9$ & $18.0-19.9$ & $70-79$ \\
\hline 14 & $36.0-37.9$ & $31.0-33.9$ & $48-48.9$ & $32-32.9$ & $330-339$ & $350-359$ & $33-34$ & $27-28$ & $13.0-14.9$ & $16.0-17.9$ & $65-69$ \\
\hline 13 & $35.0-35.9$ & $30.0-30.9$ & $47-47.9$ & $31-31.9$ & $340-349$ & $360-369$ & $31-32$ & $25-26$ & $11.0-12.9$ & $14.0-15.9$ & $60-64$ \\
\hline 12 & $34.0-34.9$ & $29.0-29.9$ & $46-46.9$ & $30-30.9$ & $350-359$ & $370-379$ & $29-30$ & $23-24$ & $9.0-10.9$ & $12.0-13.9$ & $55-59$ \\
\hline 11 & $33.0-33.9$ & $28.0-28.9$ & $45-45.9$ & $29-29.9$ & $360-369$ & $380-389$ & $27-28$ & $21-22$ & $7.0-8.9$ & $11.0-11.9$ & $50-54$ \\
\hline 10 & $32.0-32.9$ & $27.0-27.9$ & $44-44.9$ & $28-28.9$ & $370-379$ & $390-399$ & $25-26$ & $19-20$ & $6.0-6.9$ & $10.0-10.9$ & $45-49$ \\
\hline 9 & $31.0-31.9$ & $26.0-26.9$ & $43-43.9$ & $27-27.9$ & $380-389$ & $400-409$ & $23-24$ & $17-18$ & $5.0-5.9$ & $9.0-9.9$ & $40-44$ \\
\hline 8 & $30.0-30.9$ & $25.0-25.9$ & $42-42.9$ & $26-26.9$ & $390-399$ & $410-419$ & $21-22$ & $15-16$ & $4.0-4.9$ & $8.0-8.9$ & $35-39$ \\
\hline 7 & $29.0-29.9$ & $24.0-24.9$ & $41-41.9$ & $25-25.9$ & $400-409$ & $420-429$ & $19-20$ & $13-14$ & $2.0-3.9$ & $7.0-7.9$ & $30-34$ \\
\hline 6 & $28.0-28.9$ & $23.0-23.9$ & $40-40.9$ & $24-24.9$ & $410-419$ & $430-449$ & $17-18$ & $11-12$ & $-1.0-1.9$ & $6.0-6.9$ & $25-29$ \\
\hline 5 & $26.0-27.9$ & $22.0-22.9$ & $39-39.9$ & $23-23.9$ & $420-439$ & $450-469$ & $15-16$ & $9-10$ & $-3.0--1.1$ & $4.0-5.9$ & $20-24$ \\
\hline 4 & $24.0-25.9$ & $21.0-21.9$ & $37-38.9$ & $22-22.9$ & $440-459$ & $470-489$ & $13-14$ & $7-8$ & $-5.0--3.1$ & $2.0-3.9$ & $15-19$ \\
\hline 3 & $22.0-23.9$ & $20.0-20.9$ & $35-36.9$ & $21-21.9$ & $460-479$ & $490-509$ & $10-12$ & $5-6$ & $-7.0--5.1$ & $0.0-1.9$ & $10-14$ \\
\hline 2 & $20.0-21.9$ & $18.0-19.9$ & $32-34.9$ & $20-20.9$ & $480-499$ & $510-529$ & $6-9$ & $3-4$ & $-10.0--7.1$ & $-3.0--0.1$ & $5-9$ \\
\hline 1 & -19.9 & -17.9 & -31.9 & -19.9 & $500-$ & $530-$ & -5 & -2 & --10.1 & $1--3.1$ & -4 \\
\hline
\end{tabular}


blood pressure $>89 \mathrm{mmHg}$; LDL-cholesterol $>159 \mathrm{mg} / \mathrm{dl}$; HDL-cholesterol < $<0 \mathrm{mg} / \mathrm{dl}$; glucose $>109 \mathrm{mg} / \mathrm{dl}$; left ventricular hypertrophy or ST-T abnormalities without abnormal ventricular conduction on ECG or a not-negative result from Master's two-step exercise test. The number of coronary risk factors for each subject was counted (Table 1).

\section{Exercise Protocol}

An ergometer exercise test was performed using a bicycle ergometer system (Stress Test System ML5000, Fukuda Denshi Co Ltd, Tokyo Japan, and Model 50, COMBI Corp, Tokyo, Japan). The ramp protocol began with a 1-min rest in the saddle, and then $20 \mathrm{Watt}(\mathrm{W})$ was loaded for $1 \mathrm{~min}$ as a warm-up, followed by a $1 \mathrm{~W}$ increase every $3 \mathrm{~s}$ until maximum exercise was reached. After the exercise, subjects cooled down with $40 \mathrm{~W}$ for $2 \mathrm{~min}$. The pedal pitch was set at $50 \mathrm{rpm}$, and the rhythm was indicated to the subjects by a beeping sound. During the exercise the ECG was recorded by the CM5 and CL leads and blood pressure was automatically measured every minute (STBP-680 Colin Corp, Komaki, Japan). The maximum exercise level was determined by 4 indicators: (1) heart rate greater than the target calculated by [220-(age)], (2) systolic blood pressure $>230$ $\mathrm{mmHg}$, (3) respiratory quotient $>1.1$, (4) oxygen uptake at leveling-off state, (5) failure to pedal at the ordered pitch ( $<40$ cycles per minute) because of exhaustion. If (4) was fulfilled, that was sufficient, otherwise at least 2 of (1), (2), (3) and (5) were considered necessary. Those who had signs of myocardial ischemia (chest pain or discomfort, abnormal ST-T depression or elevation, dangerous arrhythmias, decreasing blood pressure etc), or other dangerous signs or symptoms ceased the exercise by order of the supervising doctor and their data were excluded. Only 2
Table 3 Fitness Score From Total Fitness Points

\begin{tabular}{ccrccc}
\hline \hline \multirow{2}{*}{ Age (years) } & \multicolumn{5}{c}{ Score } \\
\cline { 2 - 6 } & \multicolumn{1}{c}{$A$} & \multicolumn{5}{c}{$C$} & $D$ & $E$ \\
\hline-24 & -109 & $108-97$ & $96-78$ & $77-66$ & $65-$ \\
$25-29$ & -103 & $102-91$ & $90-72$ & $71-60$ & $59-$ \\
$30-34$ & -97 & $96-85$ & $84-66$ & $65-54$ & $53-$ \\
$35-39$ & -91 & $90-78$ & $77-60$ & $59-48$ & $47-$ \\
$40-44$ & -83 & $82-71$ & $70-51$ & $50-39$ & $38-$ \\
$45-49$ & -74 & $73-62$ & $61-43$ & $42-31$ & $30-$ \\
$50-54$ & -66 & $65-55$ & $54-36$ & $35-23$ & $22-$ \\
$55-59$ & -58 & $57-47$ & $46-27$ & $26-14$ & $13-$ \\
$60-64$ & -49 & $48-38$ & $37-19$ & $18-7$ & $6-$ \\
\hline
\end{tabular}

A, excellent; B, good; C, fair; D, below average; E, poor.

subjects failed to complete our fitness check because of such reasons.

\section{Gas Analysis}

Expiratory gas was analyzed breath-by-breath using a gas analysis system (Oxycon, Sigma (Mijn Hardt Co Ltd), Holland). The respiratory rate (RR), volume of expired gas ( $\dot{\mathrm{V}} \mathrm{E})$, oxygen uptake $\left(\dot{\mathrm{V}}_{2}\right)$, and carbon dioxide output ( $\dot{\mathrm{V} C \mathrm{O}_{2}}$ ), were measured and other parameters such as ventilatory equivalent for $\mathrm{O}_{2}(\dot{\mathrm{V} E} / \dot{\mathrm{V}} \mathrm{O} 2)$, ventilatory equivalent for $\mathrm{CO}_{2}\left(\dot{\mathrm{V} E} / \dot{\mathrm{V}}^{-} \mathrm{O}_{2}\right)$, respiratory quotient $(\mathrm{RQ})$, end-tidal $\mathrm{O}_{2}$ tension $\left(\mathrm{PETO}_{2}\right)$ and end-tidal $\mathrm{CO}_{2}$ tension $\left(\mathrm{PETCO}_{2}\right)$ were calculated. These indices were monitored during the exercise test.

As well as the expired-gas analysis during the bicycle ergometer test, the following were measured: grip power as an index of muscle power (mean of both hands), finger reach when sitting on the floor with legs stretched as an index of

Table 4 Subgroups by Number of Risk Factors and Profile

\begin{tabular}{|c|c|c|c|c|c|c|c|c|c|c|c|}
\hline $\begin{array}{l}\text { Number of } \\
\text { risk factor }\end{array}$ & $n$ & $\begin{array}{l}\text { Age } \\
\text { (year) }\end{array}$ & $\begin{array}{c}\text { Smokers } \\
\text { (experienced) } \\
(\%)\end{array}$ & $\begin{array}{c}B M I \\
\left(\mathrm{~kg} / \mathrm{m}^{2}\right)\end{array}$ & $\begin{array}{c}\text { Systolic } \\
B P \\
(\mathrm{mmHg})\end{array}$ & $\begin{array}{c}\text { Diastolic } \\
B P \\
(\mathrm{mmHg})\end{array}$ & $\begin{array}{c}\text { Abnormal } \\
\text { ECG } \\
(\%)\end{array}$ & $\begin{array}{c}\text { HDL- } \\
\text { cholesterol } \\
\text { (mg/dl) }\end{array}$ & $\begin{array}{l}\text { LDL- } \\
\text { cholesterol } \\
\text { (mg/dl) }\end{array}$ & $\begin{array}{l}\text { Glucose } \\
(\mathrm{mg} / \mathrm{dl})\end{array}$ & $\begin{array}{c}\dot{V} O_{2 m a x} \\
\left(\mathrm{ml} \cdot \mathrm{kg}^{-1} \cdot \mathrm{min}^{-1}\right)\end{array}$ \\
\hline \multicolumn{12}{|l|}{ Men } \\
\hline 1 & 86 & $46.9 \pm 13.5$ & 0.0 & $22.0 \pm 1.8$ & $120 \pm 11$ & $73 \pm 9$ & 0.0 & $57.2 \pm 12$ & $106 \pm 21$ & $105 \pm 17$ & $30.7 \pm 6$ \\
\hline 2 & 433 & $51.6 \pm 10.4$ & 73.9 & $22.9 \pm 2.2$ & $123 \pm 13$ & $75 \pm 9$ & 3.7 & $53.1 \pm 12$ & $118 \pm 30$ & $109 \pm 22$ & $29.0 \pm 6$ \\
\hline 3 & 180 & $52.0 \pm 9.0$ & 65.2 & $24.2 \pm 2.7$ & $126 \pm 15$ & $78 \pm 11$ & 8.3 & $48.6 \pm 12$ & $133 \pm 32$ & $112 \pm 21$ & $27.9 \pm 6$ \\
\hline 4 & 210 & $51.7 \pm 9.6$ & 84.8 & $25.6 \pm 2.7$ & $133 \pm 16$ & $82 \pm 11$ & 21.4 & $48.0 \pm 13$ & $144 \pm 34$ & $116 \pm 24$ & $26.1 \pm 6$ \\
\hline 5 & 27 & $49.0 \pm 10.3$ & 92.6 & $26.1 \pm 2.0$ & $138 \pm 18$ & $83 \pm 14$ & 22.2 & $45.4 \pm 13$ & $142 \pm 31$ & $118 \pm 18$ & $24.2 \pm 6$ \\
\hline 6 & 9 & $55.4 \pm 9.1$ & 100.0 & $28.1 \pm 2.6$ & $149 \pm 7$ & $95 \pm 8$ & 33.3 & $39.2 \pm 9$ & $173 \pm 40$ & $125 \pm 40$ & $21.2 \pm 6$ \\
\hline Total & 945 & $51.2 \pm 10.3$ & 67.3 & $23.7 \pm 2.7$ & $126 \pm 15$ & $77 \pm 11$ & 10.0 & $50.5 \pm 12$ & $126 \pm 33$ & $113 \pm 24$ & $28.5 \pm 6$ \\
\hline \multicolumn{12}{|l|}{ Women } \\
\hline 0 & 60 & $48.4 \pm 12.6$ & 1.7 & $21.0 \pm 2.1$ & $111 \pm 11$ & $68 \pm 11$ & 0.0 & $64.6 \pm 15$ & $108 \pm 21$ & $94 \pm 6$ & $25.9 \pm 5$ \\
\hline 1 & 89 & $53.0 \pm 10.0$ & 6.6 & $22.1 \pm 3.4$ & $119 \pm 14$ & $73 \pm 14$ & 12.1 & $64.3 \pm 16$ & $136 \pm 42$ & $98 \pm 12$ & $25.7 \pm 5$ \\
\hline 2 & 72 & $54.9 \pm 8.2$ & 13.9 & $23.6 \pm 3.3$ & $129 \pm 19$ & $80 \pm 19$ & 26.8 & $62.9 \pm 18$ & $154 \pm 38$ & $103 \pm 17$ & $23.5 \pm 5$ \\
\hline 3 & 28 & $54.0 \pm 7.6$ & 10.7 & $26.4 \pm 3.4$ & $136 \pm 19$ & $84 \pm 19$ & 25.0 & $54.7 \pm 10$ & $151 \pm 29$ & $114 \pm 21$ & $22.6 \pm 5$ \\
\hline 4 & 14 & $54.6 \pm 9.0$ & 21.4 & $27.1 \pm 3.0$ & $139 \pm 17$ & $88 \pm 17$ & 14.3 & $54.9 \pm 14$ & $168 \pm 30$ & $115 \pm 10$ & $21.6 \pm 5$ \\
\hline 5 & 3 & $52.3 \pm 14.6$ & 33.3 & $26.2 \pm 1.1$ & $139 \pm 8$ & $91 \pm 8$ & 66.7 & $59.0 \pm 24$ & $147 \pm 4$ & $119 \pm 9$ & $18.4 \pm 3$ \\
\hline Total & 266 & $51.4 \pm 11.1$ & 9.6 & $23.2 \pm 3.4$ & $124 \pm 17$ & $76 \pm 11$ & 17.1 & $60.0 \pm 15$ & $143 \pm 38$ & $113 \pm 19$ & $28.5 \pm 5$ \\
\hline
\end{tabular}

(Men) Significant differences $(p<0.05)$ were noticed in the following pairs; RF1-RF2, RF1-RF3 and RF1-RF6 in age, RF1-RF2, RF1-RF3, RF1-RF4, RF1RF5, RF1-RF6, RF2-RF3, RF2-RF4, RF2-RF5, RF3-RF4, RF3-RF5 and RF3-RF6 in smokers rate, every pair except RF4-RF5 in BMI, systolic BP, and diastolic BP, RF1-RF3, RF1-RF4, RF1-RF5, RF2-RF4, RF2-RF5, RF2-RF6, RF3-RF4, RF3-RF5 and RF3-RF6 in abnormal ECG, RF1-RF2, RF1-RF3, RF1RF4, RF1-RF5, RF1-RF6, RF2-RF3, RF2-RF4, RF2-RF5, RF2-RF6, RF3-RF6 and RF4-RF6 in HDL-cholesterol, every pair except RF3-RF5 and RF4-RF5 in LDL-cholesterol, and RF1-RF3, RF1-RF4, RF1-RF5, RF1-RF6, RF2-RF3, RF2-RF4, RF2-RF5 and RF2-RF6 in glucose. (Women) Significant differences $(p<0.05)$ were noticed in the following pairs; $R F 0-R F 1, R F 0-R F 2, R F 0-R F 3$ and $R F 0-R F 4$ in age, $R F 0-R F 2$ and $R F 0-R F 4$ in somokers rate, $R F 0-R F 1, R F 0$ RF2, RF0-RF3, RF0-RF4, RF0-RF5, RF1-RF2, RF1-RF3, RF1-RF4, RF1-RF5, RF2-RF3 and RF2-RF4 in BMI and systolic BP, RF0-RF1, RF0-RF2, RF0$R F 3, R F 0-R F 4, R F 0-R F 5, R F 1-R F 2, R F 1-R F 3, R F 1-R F 4, R F 1-R F 5$ and $R F 2-R F 4$ in diastolic BP, $R F 0-R F 1, R F 0-R F 2, R F 0-R F 3, R F 0-R F 5, R F 1-R F 2, R F 1-$ RF5, RF3-RF5 and RF4-RF5 in abnormal ECG, RF0-RF3, RF0-RF4, RF1-RF3, RF1-RF4 and RF2-RF3 in HDL-cholesterol, RF0-RF1, RF0-RF2, RF0-RF3, RFO-RF4, RF0-RF5, RF1-RF2, RF1-RF3 and RF1-RF4 in LDL-cholesterol, and RF0-RF2, RF0-RF3, RF0-RF4, RF0-RF5, RF1-RF2, RF1-RF3, RF1-RF4, $R F 1-R F 5, R F 2-R F 3, R F 2-R F 4$ and $R F 2-R F 5$ in glucose. 
Table 5 Subgroups by Age-Adjusted VंO2max Quartile and Profile

\begin{tabular}{|c|c|c|c|c|c|c|c|c|c|c|}
\hline $\begin{array}{l}\text { Age-adjusted } \\
\dot{\text { VO2max quartile }}\end{array}$ & $n$ & $\begin{array}{c}\text { Age } \\
\text { (years) }\end{array}$ & $\begin{array}{c}\text { Smokers } \\
\text { (experienced) } \\
(\%)\end{array}$ & $\begin{array}{c}B M I \\
\left(\mathrm{~kg} / \mathrm{m}^{2}\right)\end{array}$ & $\begin{array}{c}\text { Systolic } \\
B P \\
(\mathrm{mmHg})\end{array}$ & $\begin{array}{c}\text { Diastolic } \\
\text { BP } \\
(\mathrm{mmHg})\end{array}$ & $\begin{array}{c}\text { Abnormal } \\
\text { ECG } \\
(\%)\end{array}$ & $\begin{array}{l}\text { HDL- } \\
\text { cholesterol } \\
(\mathrm{mg} / \mathrm{dl})\end{array}$ & $\begin{array}{l}\text { LDL- } \\
\text { cholesterol } \\
(\mathrm{mg} / \mathrm{dl})\end{array}$ & $\begin{array}{l}\text { Glucose } \\
(\mathrm{mg} / \mathrm{dl})\end{array}$ \\
\hline \multicolumn{11}{|l|}{ Men } \\
\hline 1: Low & 411 & $50.9 \pm 10.3$ & 67.8 & $24.7 \pm 2.9$ & $133 \pm 16$ & $82 \pm 9$ & 13.6 & $48.8 \pm 12.1$ & $130 \pm 34$ & $118 \pm 26$ \\
\hline 2: Middle low & 410 & $52.0 \pm 10.3$ & 69.1 & $24.0 \pm 2.8$ & $124 \pm 14$ & $77 \pm 9$ & 10.7 & $49.1 \pm 11.1$ & $127 \pm 35$ & $114 \pm 25$ \\
\hline 3: Middle high & 433 & $52.0 \pm 10.1$ & 64.5 & $23.4 \pm 2.3$ & $122 \pm 14$ & $76 \pm 11$ & 7.0 & $50.0 \pm 11.9$ & $125 \pm 31$ & $111 \pm 23$ \\
\hline 4: High & 405 & $50.5 \pm 10.6$ & 67.6 & $22.7 \pm 2.3$ & $133 \pm 12$ & $74 \pm 11$ & 8.4 & $53.8 \pm 13.4$ & $124 \pm 31$ & $107 \pm 18$ \\
\hline Tatal & 1,659 & $51.3 \pm 10.3$ & 67.3 & $23.7 \pm 2.7$ & $126 \pm 15$ & $77 \pm 11$ & 10.0 & $50.5 \pm 12.3$ & $126 \pm 33$ & $113 \pm 24$ \\
\hline \multicolumn{11}{|l|}{ Women } \\
\hline 1: Low & 156 & $51.9 \pm 11.3$ & 13.9 & $25.0 \pm 3.9$ & $131 \pm 17$ & $80 \pm 11$ & 18.4 & $56.8 \pm 14.1$ & $147 \pm 39$ & $106 \pm 22$ \\
\hline 2: Middle low & 155 & $52.2 \pm 10.4$ & 4.5 & $23.8 \pm 3.5$ & $125 \pm 19$ & $77 \pm 11$ & 20.0 & $58.9 \pm 13.1$ & $147 \pm 36$ & $105 \pm 22$ \\
\hline 3: Middle high & 170 & $51.4 \pm 11.0$ & 10.9 & $22.7 \pm 2.9$ & $121 \pm 17$ & $74 \pm 10$ & 16.1 & $61.1 \pm 15.1$ & $143 \pm 38$ & $102 \pm 16$ \\
\hline 4: High & 148 & $50.1 \pm 11.6$ & 8.8 & $22.0 \pm 2.8$ & $119 \pm 15$ & $73 \pm 11$ & 13.7 & $63.0 \pm 15.9$ & $137 \pm 37$ & $99 \pm 12$ \\
\hline Total & 629 & $51.4 \pm 11.0$ & 9.6 & $23.2 \pm 3.4$ & $124 \pm 15$ & $76 \pm 11$ & 17.1 & $60.1 \pm 14.8$ & $143 \pm 38$ & $103 \pm 19$ \\
\hline
\end{tabular}

(Men) Significant differences $(p<0.05)$ were noticed in the following pairs; 2-4 and 3-4 in age, no pairs in smokers rate, every pair of BMI, systolic BP, and diastolic BP, 1-3 and 1-4 in abnormal ECG, 1-4, 2-4 and 3-4 in HDL-cholesterol, 1-4 in LDL-cholesterol, and every pair except 2-3 in glucose. (Women) Significant differences $(p<0.05)$ were noticed in the following pairs; no pair in age, 1-2 in smokers rate, every pair of BMI, every pair except 3-4 in systolic BP, and diastolic BP, no pair in abnormal ECG, 1-3, 1-4 and 2-4 in HDL-cholesterol, 1-4 and 2-4 in LDL-cholesterol, and 1-4 and 2-4 in glucose.

Table 6 Subgroups by Fitness Score and Profile

\begin{tabular}{|c|c|c|c|c|c|c|c|c|c|c|}
\hline $\begin{array}{l}\text { Fitness } \\
\text { score }\end{array}$ & $n$ & $\begin{array}{c}\text { Age } \\
\text { (years) }\end{array}$ & $\begin{array}{c}\text { Smokers } \\
\text { (experienced) } \\
(\%)\end{array}$ & $\begin{array}{c}B M I \\
\left(\mathrm{~kg} / \mathrm{m}^{2}\right)\end{array}$ & $\begin{array}{c}\text { Systolic } \\
B P \\
(\mathrm{mmHg})\end{array}$ & $\begin{array}{c}\text { Diastolic } \\
B P \\
(\mathrm{mmHg})\end{array}$ & $\begin{array}{c}\text { Abnormal } \\
\text { ECG } \\
(\%)\end{array}$ & $\begin{array}{c}\text { HDL- } \\
\text { cholesterol } \\
\text { (mg/dl) }\end{array}$ & $\begin{array}{c}\text { LDL- } \\
\text { cholesterol } \\
\text { (mg/dl) }\end{array}$ & $\begin{array}{l}\text { Glucose } \\
(\mathrm{mg} / \mathrm{dl})\end{array}$ \\
\hline \multicolumn{11}{|l|}{ Men } \\
\hline A & 199 & $54.0 \pm 5.9$ & 68.4 & $23.4 \pm 2.1$ & $122 \pm 13$ & $76 \pm 9$ & 7.5 & $51.6 \pm 12.5$ & $125 \pm 31$ & $107 \pm 17$ \\
\hline$B$ & 264 & $50.5 \pm 7.2$ & 61.8 & $23.3 \pm 2.3$ & $124 \pm 14$ & $76 \pm 10$ & 7.6 & $53.0 \pm 13.3$ & $127 \pm 30$ & $112 \pm 25$ \\
\hline$C$ & 712 & $50.0 \pm 10.1$ & 69.6 & $23.7 \pm 2.6$ & $127 \pm 14$ & $77 \pm 11$ & 9.4 & $49.9 \pm 12.0$ & $126 \pm 32$ & $113 \pm 23$ \\
\hline$D$ & 233 & $47.0 \pm 11.8$ & 66.8 & $24.4 \pm 2.9$ & $127 \pm 14$ & $78 \pm 11$ & 12.5 & $48.6 \pm 10.7$ & $129 \pm 35$ & $118 \pm 28$ \\
\hline$E$ & 84 & $40.2 \pm 10.7$ & 73.1 & $25.4 \pm 3.8$ & $126 \pm 16$ & $76 \pm 13$ & 7.2 & $45.1 \pm 9.8$ & $122 \pm 36$ & $119 \pm 33$ \\
\hline Total & 1,492 & $51.3 \pm 10.4$ & 67.3 & $23.7 \pm 2.7$ & $126 \pm 15$ & $77 \pm 11$ & 10.0 & $50.5 \pm 12.3$ & $126 \pm 33$ & $113 \pm 24$ \\
\hline \multicolumn{11}{|l|}{ Women } \\
\hline A & 60 & $55.9 \pm 5.9$ & 6.5 & $22.0 \pm 3.0$ & $121 \pm 14$ & $75 \pm 10$ & 20.6 & $66.0 \pm 16.0$ & $138 \pm 32$ & $99 \pm 10$ \\
\hline$B$ & 97 & $54.6 \pm 7.2$ & 6.1 & $22.5 \pm 2.8$ & $122 \pm 14$ & $75 \pm 10$ & 7.8 & $60.7 \pm 13.8$ & $145 \pm 36$ & $102 \pm 16$ \\
\hline$C$ & 235 & $50.1 \pm 10.1$ & 10.8 & $23.4 \pm 3.3$ & $124 \pm 18$ & $76 \pm 12$ & 19.0 & $59.1 \pm 14.3$ & $142 \pm 39$ & $103 \pm 20$ \\
\hline$D$ & 70 & $44.4 \pm 11.9$ & 20.3 & $23.5 \pm 3.8$ & $121 \pm 16$ & $75 \pm 13$ & 17.2 & $60.0 \pm 15.4$ & $139 \pm 42$ & $105 \pm 25$ \\
\hline$E$ & 37 & $39.3 \pm 10.8$ & 13.9 & $24.4 \pm 4.7$ & $125 \pm 18$ & $75 \pm 12$ & 15.6 & $53.7 \pm 12.2$ & $127 \pm 31$ & $101 \pm 18$ \\
\hline Total & 499 & $51.3 \pm 11.1$ & 9.6 & $23.2 \pm 3.4$ & $124 \pm 17$ & $76 \pm 11$ & 17.1 & $60.1 \pm 14.8$ & $143 \pm 38$ & $103 \pm 19$ \\
\hline
\end{tabular}

$(M e n)$ Significant differences $(p<0.05)$ were noticed in the following pairs; every pair except $B-D$ in age, $B-C$ in smokers rate, every pair except $A-B$ and $A-C$ in BMI, A-C, A-D, A-E, B-C and B-D in systolic BP, A-C, A-D and B-D in diastolic BP, no pair in abnormal ECG, A-D, A-E, B-C, B-D, B-E, C-E and D-E in $H D L$-cholesterol, no pair in $L D L$-cholesterol, and $A-B, A-C, A-D, A-E, B-D, B-E$ and $C-D$ in glucose. (Women) Significant differences ( $p<0.05)$ were noticed in the following pairs; every pair except $A-B$ in age, $A-D, B-D$ and $C-D$ in smokers rate, $A-C, A-D, A-E, B-C, B-D$ and $B-E$ in $B M I$, no pair in systolic BP and in diastolic BP, $A-B$ and $B-C$ in abnormal $E C G, A-B, A-C, A-D, A-E, B-E, C-E$ and $D-E$ in HDL-cholesterol, $B-E$ and $C$-E in LDL-cholesterol, and none in glucose.

flexibility, reaction time as an index of quickness, duration of standing on one foot with eyes closed for balance, and the number of rapid sit-ups achieved in 1 min as a test of muscle endurance. The results were converted into point scores (Table 2) and summed to get the total fitness score (Table 3). These Tables are based on the physical tests conducted by the Ministry of Education and Science.

Subjects were also divided into groups according to the number of risk factors they had: 4 groups by maximum oxygen uptake ( $\mathrm{V}_{2}$ max) quartile, or 5 groups by the fitness score. In order to exclude the influence of age, $\dot{\mathrm{V}} \mathrm{O}_{2} \mathrm{max}$ was age-adjusted according to a regression equation:

$$
\begin{aligned}
& \dot{\mathrm{V}} \mathrm{O}_{2 m a x}=84.521-32.794 \times \log _{10}(\text { age }) \\
& \text { in men }\left(r^{2}=0.212\right) \text {, and } \\
& \dot{\mathrm{V}} \mathrm{O}_{2 m a x}=63.363-22.078 \times \log _{10}(\text { age }) \\
& \text { in women }\left(r^{2}=0.271\right) \text {. }
\end{aligned}
$$

The serum CRP concentration and WBC were compared among these groups by (1) the number of coronary risk factors, (2) $\dot{\mathrm{V}}_{2}$ max quartile, and (3) fitness score.

\section{Statistical Analysis}

All the numerical data were assessed using Stat View (Abacus Concept Inc, Berkeley, CA, USA), and Excel (Microsoft Corp, Redmond, WA, USA). Values are expressed as mean with standard deviation (SD). In order to normalize the distribution of measured data, measured values were converted by proper equation (ie, $\log X$ for WBC and blood glucose, $X^{1 / 3}$ for HDL-cholesterol, LDLcholesterol and CRP). Statistical analysis for the differences in age or risk factors (converted values) between any 2 of the groups was performed by analysis of variance with Scheffe's test as a post hoc test. Results were considered as significant if $\mathrm{p}<0.05$. 


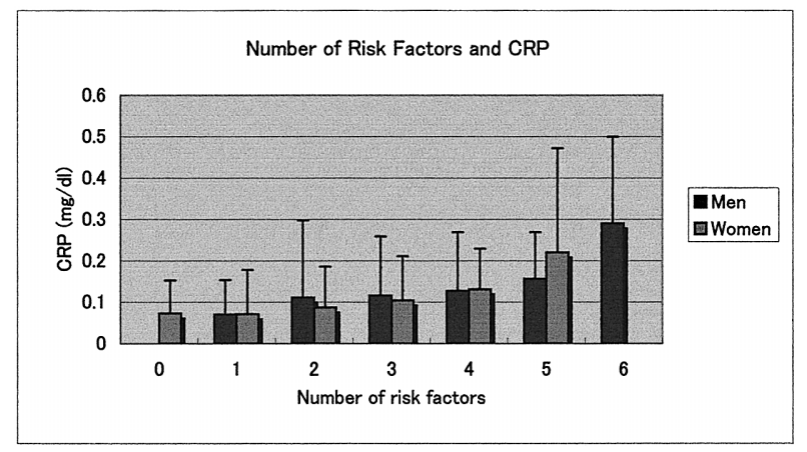

Fig 1. Number of coronary risk factors and C-reactive protein (CRP). The more coronary risk factors the higher the CRP concentration. Significant differences $(\mathrm{p}<0.05)$ were noticed in the following pairs: RF1-RF2, RF1-RF3, RF1-RF4, RF1-RF5, RF1-RF6, RF2-RF3, RF2-RF4, RF2-RF5, RF2-RF6, RF3-RF5, RF3-RF6 and RF4-RF5 in men, and RF0-RF4, RF0-RF5, RF1-RF3, RF1-RF4 and RF1-RF5 in women.

\section{Results}

The number of risk factors (RF) of each subject ranged from 1 to 6 (average, 2.67 \pm 1.07 ) in men, and from 0 to 5 (average $1.45 \pm 1.20$ ) in women. The mean ages of each group of both genders were higher in those who had more risk factors. Those with more risk factors had generally worse values for the risk factors as well as a lower $\dot{V}_{2}$ max. Among them the difference in the rate of smokers in the men varied greatly, from $0 \%$ in RF1 to $100 \%$ in RF6. Significant differences were noticed in many of the factors (Table 4). In groups with a lower $\dot{\mathrm{V}} 2$ max or fitness score, more risk factors were observed (Tables 5,6). In groups analyzed by fitness score, we found that the higher the score, the older the subject and this was very characteristic of the study subjects, which we will discuss later.

In our data CRP concentration and WBC did not correlate with age in either gender $\left(r^{2}=0.001\right)$. Both CRP and WBC were slightly (but not significant) higher in the subjects in their 40's or 50's than those in their 20's, 30's, 60 's or 70's.

The crude mean value of CRP was higher in the groups with more risk factors, lower $\dot{\mathrm{VO}}_{2}$ max quartile and the lower fitness score for both genders. Mean values of CRP

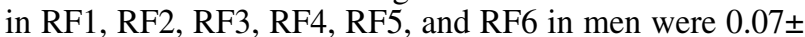
$0.084,0.111 \pm 0.187,0.116 \pm 0.143,0.127 \pm 0.142,0.156 \pm$ 0.113 , and $0.29 \pm 0.21$, respectively (Fig 1 ), and for women in RF0, RF1, RF2, RF3, RF4, and RF5 were $0.073 \pm 0.08$, $0.071 \pm 0.107,0.087 \pm 0.099,0.104 \pm 0.107,0.131 \pm 0.098$, and $0.22 \pm 0.252$. The mean CRP in $\dot{\mathrm{V} O} 2$ max quartile were, from the higher one, $0.103 \pm 0.166,0.119 \pm 0.167,0.145 \pm 0.225$, and $0.137 \pm 0.213$ in men, and $0.103 \pm 0.148,0.107 \pm 0.12$, $0.122 \pm 0.127$, and $0.133 \pm 0.182$ in women (Fig 2$)$. The mean CRP in the groups by fitness score were, from the higher score, $0.087 \pm 0.092,0.104 \pm 0.175,0.125 \pm 0.165,0.142 \pm$ 0.195 , and $0.182 \pm 0.239$ in men, and $0.114 \pm 0.097,0.102 \pm$ $0.093,0.111 \pm 0.135,0.133 \pm 0.181$, and $0.094 \pm 0.092$ in women (Fig 3). A stepwise increase in CRP was noticed in men according to the category of RF.

The distribution of CRP concentration showed the same tendency; in the group with less risk factors, higher $\dot{\mathrm{V}}{ }_{2}$ max quartile, or higher fitness score, fewer subjects were over the normal range, and the majority less than 0.06 mg/dl (Figs 4-6).

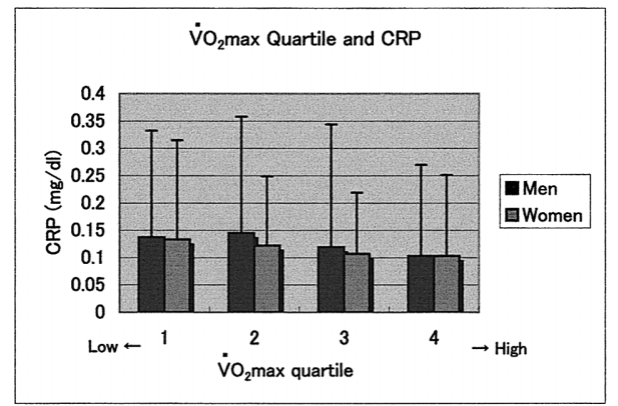

Fig 2. Quartiles of age-adjusted $\dot{\mathrm{V}} \mathrm{O}_{2} \mathrm{max}$ and C-reactive protein (CRP). The highest quartile of age-adjusted $\dot{\mathrm{V}} \mathrm{O}_{2}$ max (4 in this figure) showed the lowest CRP in both genders. Significant differences $(\mathrm{p}<0.05)$ were noticed in the following pairs: $1-4,2-4$ and 3-4 in men and $2-3$ and $2-4$ in women.

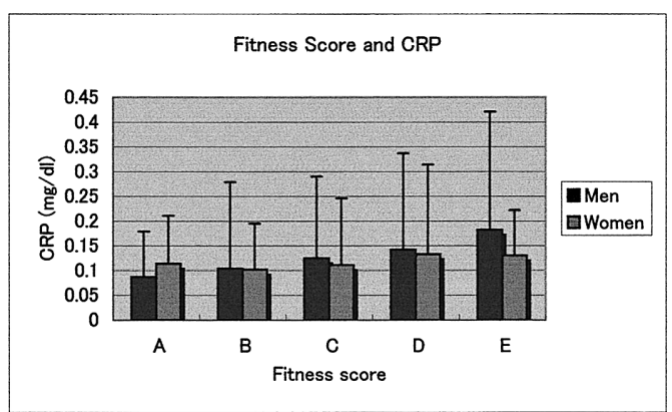

Fig 3. Fitness score and C-reactive protein (CRP). The Excellent (A in this figure) male subgroup and Good (B in the figure) female subgroup showed the lowest CRP. Significant differences $(p<0.05)$ were noticed in the following pairs: A-C, A-D, A-E, B-C, B-D, $\mathrm{B}-\mathrm{E}, \mathrm{C}-\mathrm{E}$ in men and none in women.

The same tendency was observed for WBC (Figs 7-9). Subjects with more coronary risk factors, lower $\dot{\mathrm{VO}}_{2} \mathrm{max}$ quartile, or lower fitness score had a higher WBC for both genders. The mean values of WBC in RF1, RF2, RF3, RF4, RF5, and RF6 in men were 4,869 $\pm 955,5,596 \pm 1,424$, $6,159 \pm 1,606,6,187 \pm 1,565,7,096 \pm 2,008$, and 6,878 $\pm 1,538$, respectively, and for women in RF0, RF1, RF2, RF3, RF4, and RF5 they were $5,075 \pm 120,5,066 \pm 1,012,5,136 \pm 1,128$, $5,418 \pm 1,476,6,793 \pm 2,351$, and 5,700 $\pm 1,082$. The mean WBC in $\dot{\mathrm{V}} \mathrm{O}_{2}$ max quartile were, from the higher one, $5,735 \pm 1,494,5,898 \pm 1,576,5,677 \pm 1,498$, and 5,501 $\pm 1,583$ in men, and $5,312 \pm 1,415,5,297 \pm 1,384,5,105 \pm 1,310$, and $5,037 \pm 1,222$ in women; by fitness score were, from the higher score, 5,267 $\pm 1,237,5,383 \pm 1,437,5,865 \pm 1,547$, $6,063 \pm 2,587$, and $6,514 \pm 1,898$ in men, and 5,125 $\pm 1,348$, $4,939 \pm 1,281,5,261 \pm 1,270,5,321 \pm 1,458$, and 5,971 $\pm 1,927$ in women.

Both CRP and WBC were higher in men, and their relationships to $\dot{\mathrm{V}} \mathrm{O}_{2} \mathrm{max}$, fitness score, and coronary risk factor number were more distinctive than in women. CRP and WBC were, as a whole, higher in those who were considered at higher risk for coronary heart disease in either gender.

\section{Discussion}

We have demonstrated a positive correlation of either serum CRP concentration or WBC to the number of coronary risk factors, and a negative correlation of those inflammatory indices to $\dot{\mathrm{V}} \mathrm{O}_{2}$ max or total fitness score. These 

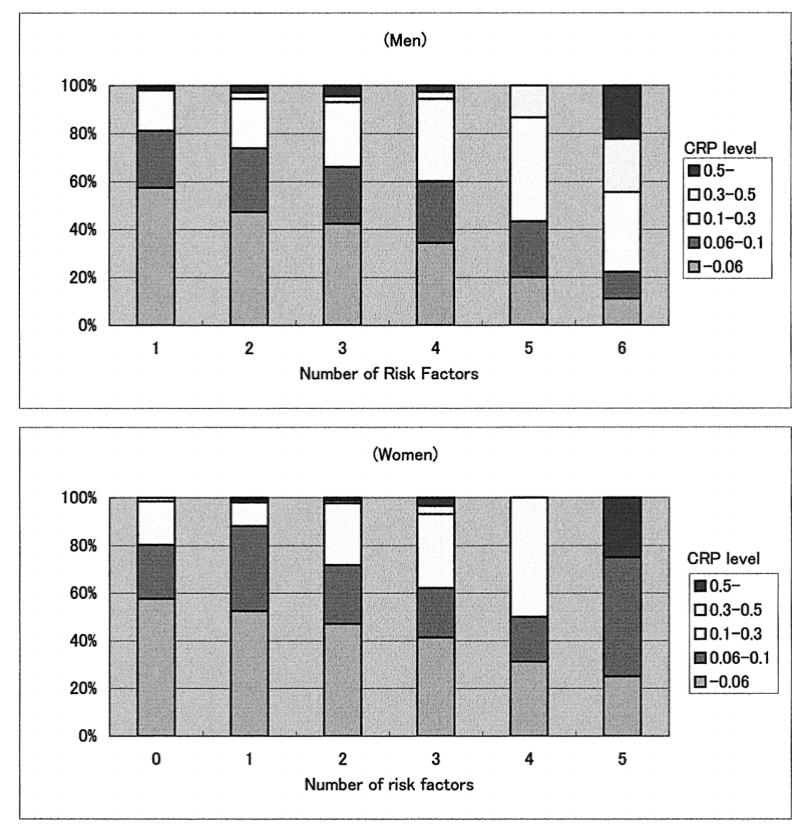

Fig 4. Distribution of C-reactive protein (CRP) levels by number of coronary risk factors. The more risk factors, the lower the category of CRP decreases.

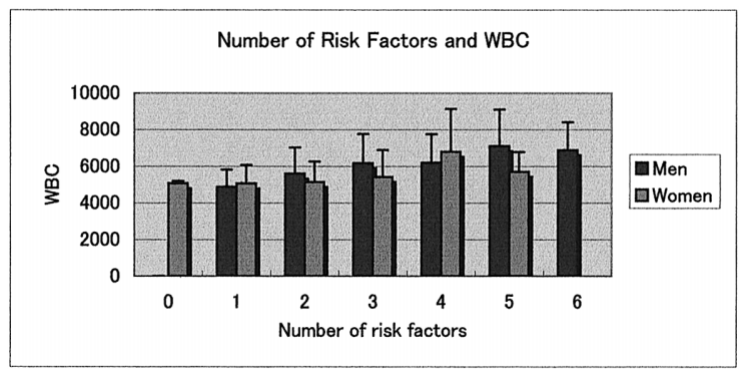

Fig 7. Number of risk factors and white blood cell count (WBC). Similar to CRP, WBC was higher in subgroups with more risk factors. Significant differences $(\mathrm{p}<0.05)$ were noticed in the following pairs: RF1-RF2, RF1-RF3, RF1-RF4, RF1-RF5, RF1-RF6, RF2-RF3, RF2-RF4, RF2-RF5, RF2-RF6, RF3-RF5 and RF4-RF5 in men, and RF0-RF4, RF1-RF4, RF2-RF4 and RF3-RF4 in women.

results suggest that high-risk coronary subjects are in an inflammatory, but despite the increasing number of reports on CRP and coronary risk ${ }^{2-5}$ the precise mechanisms of how inflammation leads to atherosclerosis remain unclear. The present results for CRP and WBC in a large group of apparently healthy Japanese support these recent findings of a relationship between inflammation and coronary atherosclerotic risk.

The background profile of our study subjects varied significantly among each group with respect to age and some risk factors. The older subjects had more risk factors, but on the other hand in groups with the lower fitness score the age was younger (Tables 4-6). Of the elderly, those who wanted to take the fitness check would be stronger than the average elderly person who would not be so healthy, active and energetic as to take a fitness check and so this specific characteristic of our study subjects may have influenced the results. However, higher CRP and WBC scores were found in those with more coronary risk
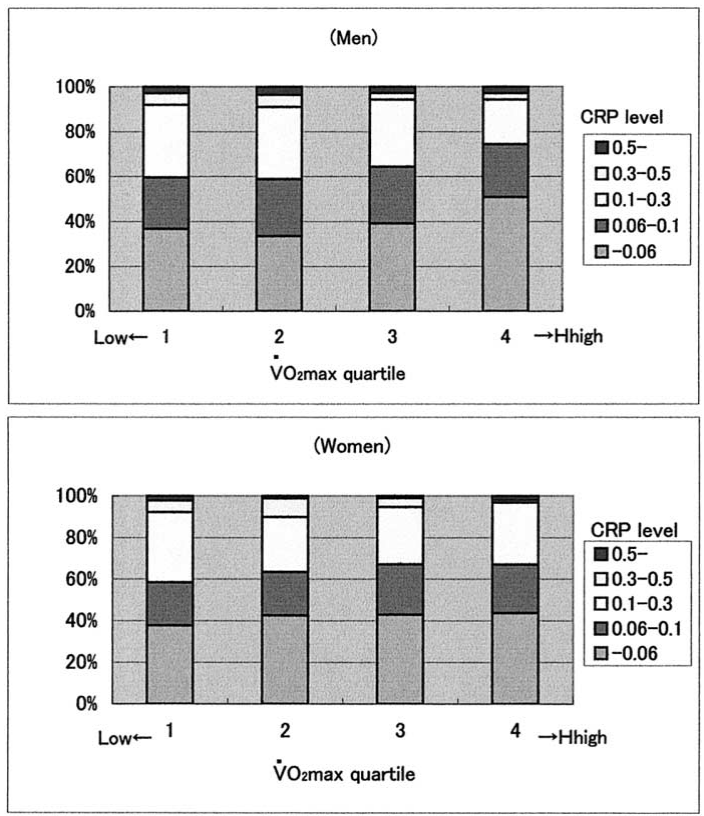

Fig 5. Distribution of C-reactive protein (CRP) levels by $\dot{V}_{2}$ max quartile. The rate of the lower category of CRP is higher in the highest quartile of age-adjusted $\dot{\mathrm{V}} \mathrm{O}_{2} \max$ (4 in this figure).

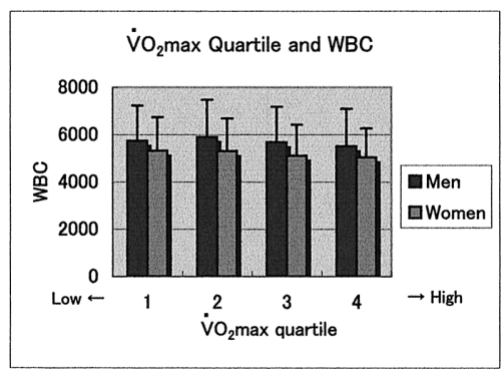

Fig 8. $\dot{\mathrm{V}} \mathrm{O}_{2} \mathrm{max}$ quartile and white blood cell count (WBC). Those in the higher quartile had a tendency to show a lower WBC. Significant differences $(\mathrm{p}<0.05)$ were noticed in the following pairs: $1-2,1-3$, $1-4,2-4$ and 3-4 in men, and 1-3 and 1-4 in women.

factors (older age), lower $\dot{\mathrm{V}} \mathrm{O}_{2}$ max quartile and lower fitness score group (younger age). Thus the differences in age among the groups did not greatly influence the relationship of CRP or WBC to coronary risk. On the other hand, individual values for coronary risk factors showed differences (some of them statistically significant) among the groups analyzed by number of risk factors, $\dot{\mathrm{V}} \mathrm{O}_{2}$ max level, or fitness score. The risk factors were higher or worse in the group with more coronary risk factors, in the group with a lower $\dot{\mathrm{V}} \mathrm{O}_{2}$ max quartile and in the group with lower fitness score ${ }^{15}$ which implies that a higher CRP or WBC is dependent on other coronary risk factors and reconfirms other reports that some inflammatory process is connected with the high risk of a coronary event ${ }^{16}$

Our CRP data were not obtained by highly sensitive measurement, but are similar to those in a recent report by Hashimoto et al ${ }^{17}$ who used a highly sensitive method. Their mean value of CRP at base line was $0.15 \pm 0.21 \mathrm{mg} / \mathrm{dl}$ and their overall CRP data are only a little higher than ours $(0.13 \pm 0.20 \mathrm{mg} / \mathrm{dl}$ in men, $0.12 \pm 0.14 \mathrm{mg} / \mathrm{dl}$ in women $)$, probably because of subject number and background. Their 

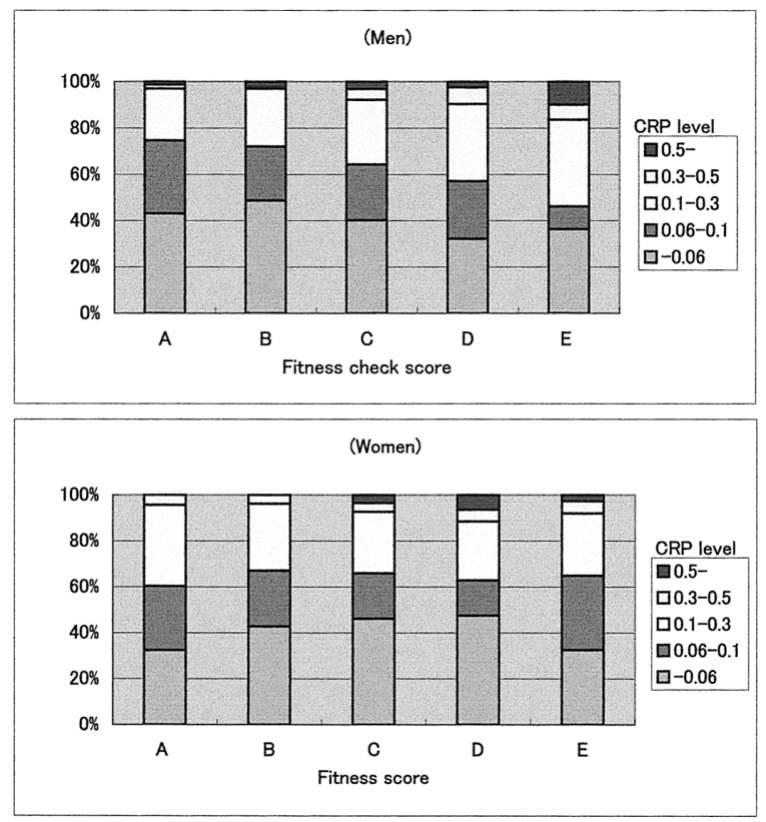

Fig 6. Distribution of C-reactive protein (CRP) levels by fitness score. The rate of the higher category of CRP increases in men in accordance with the lower fitness score; however, this correlation was not so distinct in women.

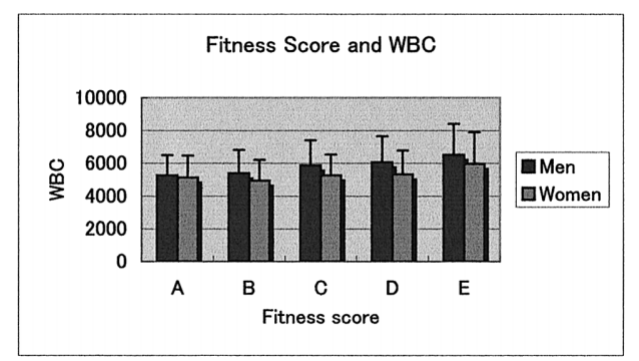

Fig 9. Fitness score and white blood cell count (WBC). Excellent (A in this figure) male subjects and Good (B in the figure) female subjects showed the fewest WBC. Significant differences $(p<0.05)$ were noticed in the following pairs: A-B, A-C, A-D, A-E, B-C, $\mathrm{B}-\mathrm{D}, \mathrm{B}-\mathrm{E}$ and $\mathrm{C}-\mathrm{E}$ in men and $\mathrm{A}-\mathrm{E}, \mathrm{B}-\mathrm{C}, \mathrm{B}-\mathrm{D}, \mathrm{B}-\mathrm{E}, \mathrm{C}-\mathrm{E}$ and $\mathrm{D}-\mathrm{E}$ in women.

data were obtained from 179 outpatients, whereas ours are from apparently healthy subjects and taking this into consideration, the difference is reasonable. According to our results, conventional CRP measurement (not a highly sensitive technique), which is lower in cost, would be enough to assess the risk of a subject; for example, in the present study, using a CRP concentration with cut-off level of 0.14 $\mathrm{mg} / \mathrm{dl}$ could screen male subjects with more than 6 coronary risk factors, in which the sensitivity was $77.8 \%$ and the specificity was $79.6 \%$.

In addition to CRP, WBC also showed a similar relation to the number of coronary risk factors or physical fitness and also confirmse recent findings that some inflammatory process is connected to with high-risk coronary outcome or the atherosclerotic process of arteries. ${ }^{1-5,16}$

More interesting is the correlation of CRP and WBC to physical fitness and we believe ours to be the first report of this association in Japanese subjects. Good physical fitness is indispensable for a healthy and active life and lack of physical exercise is now considered a modifiable coronary risk factor. However, the mechanism of prevention of atherosclerotic progression by exercise remains unclear, although our preliminary data from a small number of subjects showed that CRP concentration decreased from $0.126 \pm 0.11$ to $0.103 \pm 0.10 \mathrm{mg} / \mathrm{dl}$ after 6 months of periodic physical exercise, together with a significant decrease in the conventional coronary risk factors (ie, body weight, blood pressure, cholesterol, glucose etc). It is unclear whether this anti-inflammatory effect of physical exercise is dependent on the decrease in another coronary risk factor or not. However, we could not explain the relationship of conventional risk factors to inflammation. Chlamydial infection, which directly causes inflammation, did not differ before and after the exercise because subjects were not under doctors' observation or taking medication. Lack of physical activity might induce inflammation of the arterial wall and the favorable effect of physical exercise on health may be through a novel mechanism; for instance, suppression of inflammation. An anti-inflammatory effect of physical training was reported in a patient with chronic heart failure, ${ }^{18}$ and in a marathon runner. ${ }^{19}$ Lower CRP concentration has been reported in highly trained athletes, ${ }^{20}$ but anaerobic exercise reportedly induces an acute phase response? ${ }^{21}$

Dental infection or periodontal disease has been suggested to be, although it is still controversial, a predictor of coronary heart disease ${ }^{22,23} \mathrm{We}$ did not examine periodontal diseases in this study, although we have previously reported an association of coronary high-risk status and lower physical fitness with periodontal disease ${ }^{24}$ The increased inflammatory state of periodontitis in high-risk subjects might come from their habitual or medical status, such as smoking, eating between meals, drinking excessively, obesity or borderline diabetes, factors that would worsen the periodontal inflammation and cause the CRP or WBC to increase. It is also well known that WBC is higher in smokers. Those with more coronary risk factors may be subject to chlamydia infection ${ }^{25}$ and that background might influence our results.

In women the relationship of CRP or WBC to coronary risk factors and fitness was not as apparent as in men, partly because of the smaller number of participants and the homogeneously low-risk characteristic. In the data $83.8 \%$ (223 in 266) of women had less than 3 risk factors, so when more women with a variety of coronary risk enter studies, there will be a clearer correlation.

\section{Study Limitations}

In our study a lower fitness score was associated with younger age, the reasons for which are unclear. It may be that younger or middle-aged people with more coronary risk factors are actively advised to undertake the fitness program at Aichi Prefectural Center for Health Care.

Our laboratory did not use a highly sensitive CRP measurement system and so our mean value may not be as correct as that obtained from a highly sensitive method, especially for the very low values. Our mean value for the total subjects was much higher than the sensitivity level of $0.06 \mathrm{mg} / \mathrm{dl}$. The higher mean value of CRP concentration for more risk factors and a lower fitness score was mainly derived from the increased number of those with a very high CRP concentration. In our CRP data, 39.9\% of men and $41.7 \%$ of women in total were below the sensitivity level of $0.06 \mathrm{mg} / \mathrm{dl}$. The distribution of the CRP concentration would support this finding. Another problem with the 
CRP measurement was the variability of data. Macy et al reported that for the within-subject variability of CRP, the coefficient of variation was $42.2 \%$, and for the betweensubject variability, the coefficient of variation was $92.5 \% 26$ Kayaba et al pointed out that the correlation coefficient of CRP between baseline and follow-up measurements was $0.433^{27}$ These values cannot be overlooked in discussing the lower level of CRP. According to our data, the correlation coefficient of CRP between baseline and the 6-month follow-up was 0.36 in the 279 subjects who participated our exercise program of the Center, which was not so different from the result of Kayaba et al27 The correlation coefficient of WBC was 0.69 in the same subjects. Root mean square differences of them were 0.12 in CRP and 1,068 in WBC. When considering that the mean value of CRP in total was 0.13 in men and 0.12 in women, and the mean value of WBC in total were 5,189 in men and 5,703 in women, the root mean square difference of WBC was relatively smaller than that of CRP. Although WBC is known to have values of wide intra-individual variation, these results mean WBC is less variable than CRP. These variations will be cancelled out in larger population studies. Further study is required to clarify the precise mechanism by which inflammation affects the progress of atherosclerosis.

\section{References}

1. Ross R. Atherosclerosis: An inflammtory disease. N Engl J Med 1999; 340: $115-126$.

2. Mendall MA, Patel P, Ballam L, Strachan D, Northfield TC. C-reactive protein and its relation to cardiovascular risk factors: A population based cross sectional study. BMJ 1996; 312: 1061-1065.

3. Koenig W, Sund M, Frohlich M, Fischer HG, Lowel H, Doring A, et al. C-reactive protein, a sensitive marker of inflammation, predicts future risk of coronary heart disease in initially healthy middle-aged men: Results from the MONICA Monitoring Trends and Determinants in Cardiovascular Disease (Augsburg Cohort Study 19841992). Circulation 1999; 99: 237-242.

4. Mendall MA, Strachan DP, Butland BK, Ballam L, Morris J, Sweetnam PM, et al. C-reactive protein: Relation to total mortality, cardiovascular mortality and cardiovascular risk factors in men. Eur Heart J 2000; 21: 1584-1590.

5. Folsom AR, Pankow JS, Tracy RP, Arnett DK, Peacock JM, Hong $\mathrm{Y}$, et al. The Investigators of the NHBLI Family Heart Study: Association of C-reactive protein with markers of prevalent atherosclerotic disease. Am J Cardiol 2001; 88: 112-117.

6. Overview of cause of death. In: Kokumin-Eisei-no-Doko (Health Welfare Statistics). Tokyo; Health and Welfare Statistics Association; 2001; 48(9): 50-57.

7. Kjelsberg MO, Cutler JA, Dolecek TA. Brief description of the Multiple Risk Factor Intervention Trial. Am J Clin Nutr 1997; 65(Suppl 1): 191S-195S.

8. Kitabatake A, Itakura H, Oouchi Y, Kobayashi T, Kondo K, Saito M, et al. Guidelines for primary prevention of ischemic heart disease. Jpn Circ J 2001; 65(Suppl V): 999-1065.

9. Tobacco 2. Trend of smoking rate in Japan. In: Kokumin-Eisei-noDoko (Health Welfare Statistics). Tokyo; Health and Welfare Statistics Association; 2001; 48(9): 86.

10. Friedewald WT, Levy RI, Frederickson DS. Estimation of the concen- tration of low-density-lipoprotein cholesterol in plasma without use of the preparative ultracentrifuge. Clin Chem 1972; 18: 499-502.

11. Kaplan NM. The 6th Joint National Committee Report (JNC-6): New guidelines for hypertension therapy from the USA. Keio J Med 1998; 47: 99-105.

12. Fuster V, Gotto AM, Libby P, Loscalzo J, McGill HC. 27th Bethesda Conference: Matching the intensity of risk factor management with the hazard for coronary disease events. Task Force 1. Pathogenesis of coronary disease: The biologic role of risk factors. J Am Coll Cardiol 1996; 27: 964-976.

13. Furberg CD, Hennekens CH, Hulley SB, Manolio T, Psaty BM, Whelton PK. 27th Bethesda Conference: Matching the intensity of risk factor management with the hazard for coronary disease events. Task Force 2. Clinical epidemiology: The conceptual basis for interpreting risk factors. J Am Coll Cardiol 1996; 27: 976-978.

14. Pasternak RC, Grundy SM, Levy D, Thompson PD. 27th Bethesda Conference: Matching the intensity of risk factor management with the hazard for coronary disease events. Task Force 3 . Spectrum of risk factors for coronary heart disease. J Am Coll Cardiol 1996; 27: 978 990.

15. Ichihara Y, Hattori R, Anno T, Okuma K, Yokoi M, Mizuno Y, et al. Oxygen uptake and its relation to physical activity and other coronary risk factors in asymptomatic middle-aged Japanese. J Cardiopulm Rehabil 1996; 16: 378-385.

16. Kuller LH, Tracy RP, Shaten J, Meilahn EN. Relation of C-reactive protein and coronary heart disease in the MRFIT nested case-control study: Multiple Risk Factor Intervention Trial. Am J Epidemiol 1996; 144: $537-547$

17. Hashimoto H, Kitagawa K, Hougaku H, Shimizu Y, Sakaguchi M, Nagai $Y$, et al. C-reactive protein is an independent predictor of the rate of increase in early carotid atherosclerosis. Circulation 2001; 104: $63-67$.

18. Adamopoulos S, Parissis J, Kroupis C, Georgiadis M, Karatzas D, Karavolias G, et al. Physical training reduces peripheral markers of inflammation in patients with chronic heart failure. Eur Heart $J$ 2001; 22: $791-797$.

19. Mattusch F, Dufaux B, Heine O, Mertens I, Rost R. Reduction of the plasma concentration of C-reactive protein following nine months of endurance training. Int J Sports Med 2000; 21: 21-24.

20. Dufaux B, Order U, Geyer H, Hollmann W. C-reactive protein serum concentrations in well-trained athletes. Int J Sports Med 1984; 5: $102-106$.

21. Meyer T, Gabriel HH, Ratz M, Muller HJ, Kindermann W. Anaerobic exercise induces moderate acute phase response. Med Sci Sports Exerc 2001; 33: 549-555.

22. Beck JD, Pankow J, Tyroler HA, Offenbacher S. Dental infections and atherosclerosis. Am Heart J 1999; 138: S528-S533.

23. Howell TH, Ridker PM, Ajani UA, Hennekens CH, Christen WG. Periodontal disease and risk of subsequent cardiovascular disease in US. male physicians. J Am Coll Cardiol 2001; 37: 445-450.

24. Wakai K, Kawamura T, Umemura O, Hara Y, Machida J, Anno T, et al. Associations of medical status and physical fitness with periodontal disease. J Clin Periodontol 1999; 26: 664-672.

25. Song H, Tasaki H, Yashiro A, Yamashita K, Taniguchi H, Nakashima Y. Acute-phase proteins and Chlamydia pneumoniae infection: Which one is more important in acute coronary syndrome? Jpn Circ J 2001; 65: $853-857$.

26. Macy EM, Hayes TE, Tracy RP. Variability in the measurement of Creactive protein in healthy subjects: Implications for reference intervals and epidemiological applications. Clin Chem 1997; 43: 52-58.

27. Kayaba K, Ishikawa S, Gotoh T, Nago N, Kajii E, Nakamura Y, et al. Five-year intra-individual variability in C-reactive protein levels in a Japanese population-based study: The Jichi Medical School Cohort Study at Yamato, 1993-1998. Jpn Circ J 2000; 64: 303-308. 